\title{
Tumors of the skull base in children: review of tumor types and management strategies
}

\author{
Eve C. Tsai, M.D., Stephen Santoreneos, M.B., B.S., and James T. RutKa, M.D., Ph.D. \\ Division of Neurosurgery, The University of Toronto, Ontario, Canada
}

\begin{abstract}
Although many treatment strategies for skull base tumors in adults have been reported, relatively little has been reported regarding such therapies in the pediatric population. Skull base tumors in children present a therapeutic challenge because of their unique pathological composition, the constraints of the maturing skull and brain, and the small size of the patients. In this review, the authors examine the pediatric skull base lesions that occur in the anterior, middle, and posterior cranial base, focusing on unique pediatric tumors such as encepahalocele, fibrous dysplasia, esthesioneuroblastoma, craniopharyngioma, juvenile nasopharyngeal angiofibroma, cholesteatoma, chordoma, chondrosarcoma, and Ewing sarcoma. They review management strategies that include radio- and chemotherapy, as well as surgical approaches with emphasis on the modifications and complications associated with the procedures as they apply in children. Evidence for the advantages and limitations of radiotherapy, chemotherapy, and surgery as it pertains to the pediatric population will be examined. With a working knowledge of skull base anatomy and special considerations of the developing craniofacial skeleton, neurosurgeons can treat skull base lesions in children with acceptable morbidity and mortality rates. Outcomes in this population may be better than those in adults, in part because of the benign histopathology that frequently affects the pediatric skull base, as well as the plasticity of the maturing nervous system.
\end{abstract}

\section{KEY WORDS - skull base tumor • pediatric neurosurgery • angiofibroma • encephalocele • esthesioneuroblastoma • Ewing sarcoma • fibrous dysplasia}

Skull base tumors have been difficult to treat because of the complexity involved in approaching them. With recent technical advances and the development of specialized centers, however, removal and cure are now possible. Although many of the surgical routes developed to approach skull base tumors have been reported for adults, few such reports exist for managing these lesions in children. In general, the unique anatomy in children poses challenges for the skull base surgeon because of the constraints of the developing skull and the small size of the patients.

A few reports on skull base tumors in the pediatric population have been published. ${ }^{3,13,22,68,129,141}$ In our review of skull base tumors, fewer than $5 \%$ of all frameless stereotactic surgeries were performed for skull base lesions. ${ }^{3}$ In this article, we will review the presentation and treatment of some of the relevant tumors of the anterior, middle, and posterior skull base that occur in the pediatric population (Fig. 1). Additionally, we will examine the common surgical approaches, with particular emphasis on their modifications and complications as they apply to children.

\section{DISTINGUISHING FEATURES OF PEDIATRIC SKULL BASE TUMORS}

Pediatric skull base tumors differ from adult tumors in

Abbreviations used in this paper: CSF = cerebrospinal fluid; $\mathrm{CT}=$ computerized tomography; $\mathrm{MR}=$ magnetic resonance. many aspects. Epidemiologically in the pediatric population, there are proportionately fewer skull base lesions than in adults, and more males (69\%) than females are affected. ${ }^{129}$ This sex difference may be related to the different tumor types that occur in children, as there are considerably fewer meningiomas and more benign nerve sheath tumors. ${ }^{101,129}$ In terms of operative approach, the surgeon must be careful, because of differing anatomy and involvement of growth centers in children. For example, anterior approaches in children are hindered by the shallow anterior fossa floor and the immaturity of the sinuses. Those involving maxillotomy may require reconsideration because tooth buds can be compromised. Because tissue planes are reportedly better defined in children, a higher percentage of complete resection in the initial attempt has been noted. ${ }^{129}$ The higher rate of complete resection, together with the high incidence of benign tumors, helps to explain why a better prognosis in children with skull base lesions is often reported. ${ }^{129}$

\section{TUMORS OF THE ANTERIOR CRANIAL BASE IN CHILDREN}

Clinical findings in pediatric patients with anterior cranial base lesions are related to the tumor location and do not differ significantly from those observed in the adult population. Whereas the most common anterior cranial base tumors in adults are nasal or paranasal malignancies and meningiomas, these tumors are relatively rare in chil- 


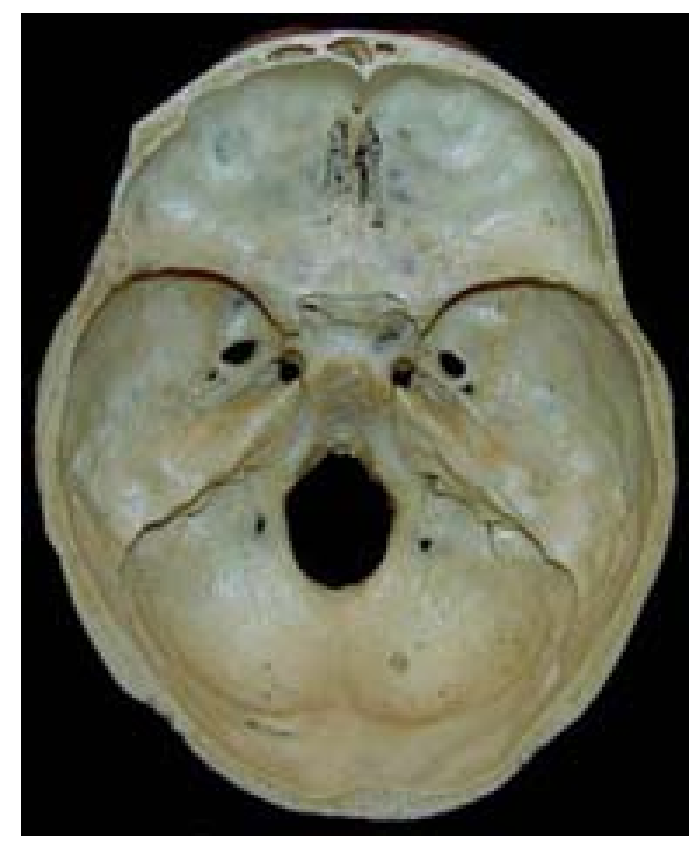

Fig. 1. Interactive figure in which the tumor and surgical approaches correspond to each skull base region. Click on a skull base region to view tumors and surgical approaches associated with this region.

dren, ${ }^{102}$ in whom the most common lesions of the anterior cranial base are encephaloceles, fibrous dysplasia, and esthesioneuroblastomas.

\section{Encephaloceles of the Anterior Cranial Fossa}

Encephaloceles are extensions of intracranial structures outside the normal confines of the skull, and their incidence is approximately 0.2 per 1000 live births and fetal deaths. ${ }^{121}$ Whereas convexity encephaloceles especially in the occipital region predominate in North America, encephaloceles of the anterior cranial fossa most frequently occur in Southeast Asia. These lesions can be classified into sincipital and basal encephaloceles. Sincipital encephaloceles can be further subdivided into frontonasal, -ethmoidal, and -orbital subtypes. Basal encephaloceles may be sphenoorbital, -maxillary, -ethmoidal, or transethmoidal. ${ }^{78}$ The University of Toronto experience with 17 sincipital and five basal encephalocoeles has previously been reported. ${ }^{78}$

Surgery-related strategies for repair of anterior cranial fossa encephaloceles usually require a bicoronal scalp incision, frontal craniotomy, and bilateral orbitotomy (Fig. 2 ). The dural defect is defined at the anterior skull base, and the dura is then opened. Normal-appearing herniated brain tissue can sometimes be restored to the intracranial compartment; however, frequently this tissue is dysplastic and irretrievable. The dura is closed in a watertight fashion, and the craniofacial skeleton is reconstructed in conjunction with the craniofacial surgeons charged with cosmetic repair of the facial skin defect. In cases in which marked hypertelorism has resulted, an orbital translocation procedure may be required.$^{78}$ In contrast to occipital encephaloceles, which are frequently associated with hy-

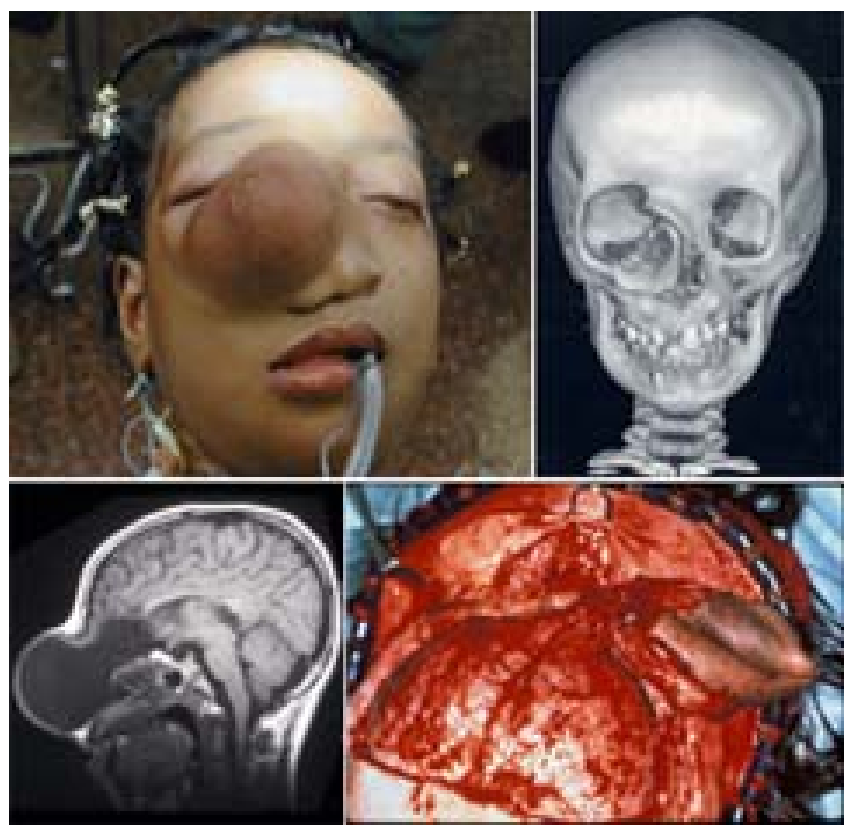

Fig. 2. Upper Left: Photograph showing a girl with large sincipital, frontoorbital encephalocele, prepared for surgery. Upper Right: Three-dimensional CT scan obtained in the same girl, demonstrating osseous erosion of medial orbit by encephalocele. Lower Left: Sagittal MR image obtained in a patient with a large predominantly cystic frontonasal mass protruding through the osseous defect. Lower Right: Intraoperative photograph demonstrating repair of nasofrontal encephalocele. A bifrontal craniotomy and bilateral orbitotomies have been performed. The encephalocele sac has been dissected free from the facial skin and is continuous with the intracranial dura.

drocephalus, marked herniation of brain tissue, and microcephaly, management of encephaloceles of the anterior cranial base usually does not require CSF diversionary procedures for hydrocephalus.

\section{Fibrous Dysplasia}

Fibrous dysplasia is a developmental anomaly of boneforming mesenchyme in which the transformation of woven bone to lamellar bone does not occur and there is an overgrowth of a well-vascularized fibrous stroma surrounding the haphazardly arranged osseous trabeculae. ${ }^{49}$ It can occur in a monostotic form, in a polyostotic form involving multiple osseous sites, and as part of the McCune-Albright syndrome. ${ }^{49}$ Consideration of aggressive surgical approaches to control disease-related complications must be weighed against the known difficulties associated with reconstructing large bone defects and patients' unpredictable clinical courses. ${ }^{27}$ Advocates for early surgery believe that conservative treatment during the "active" phase in children is unacceptable ${ }^{16}$ because there is no indication that surgical procedures inhibit the growth rate of residual normal tissues ${ }^{49}$ and progression of disease can continue into adulthood (Fig. 3). ${ }^{59}$ Therefore, surgery is indicated for the prevention of neurological deficit or substantial deformity in patients of all ages. One of the most frequent and feared complications of fibrous dysplasia of the sphenoid wing is encroachment of the optic 


\section{Skull base tumors in children}

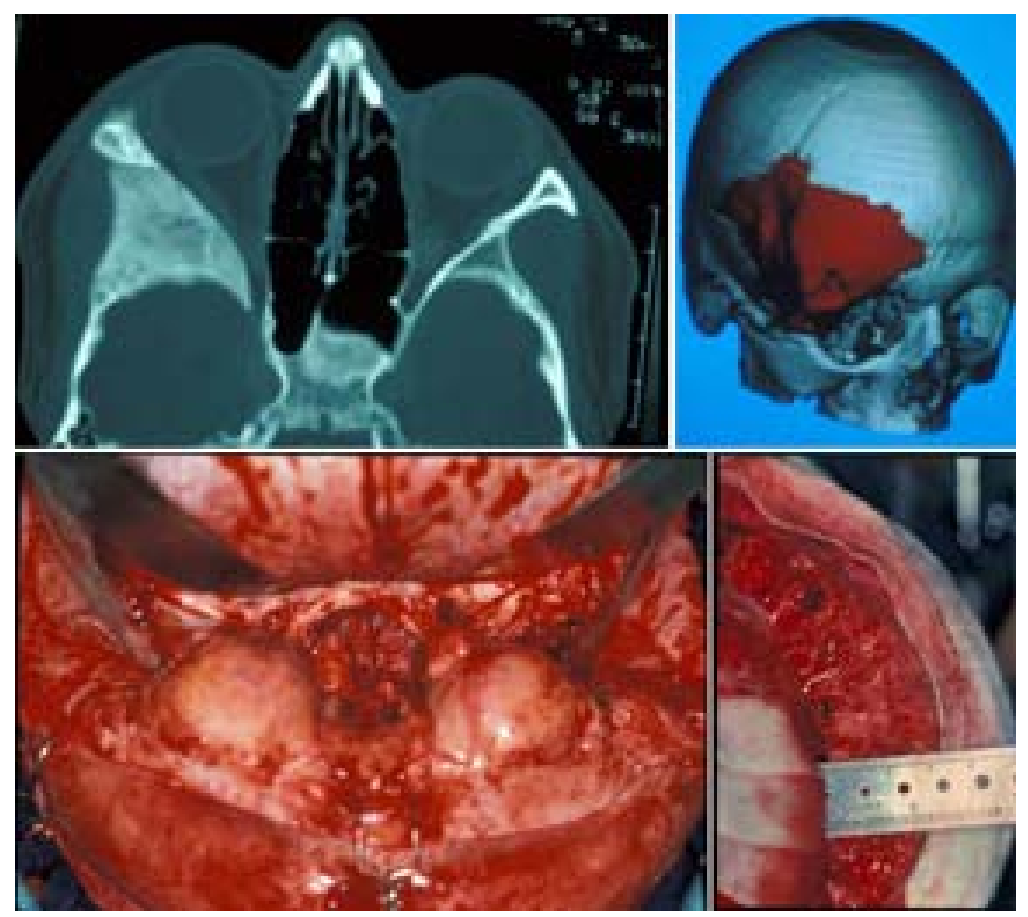

Fig. 3. Upper Left: Axial CT scan with bone windows revealing right sphenoid wing fibrous dysplasia. Upper Right: Three-dimensional CT reconstruction obtained in the same patient, revealing the involved region of the anterior cranial base. Lower Left: Intraoperative photograph of anterior cranial base fibrous dysplasia following decompression of bilateral optic nerves and orbits. Lower Right: Intraoperative photograph showing the thickness of the affected skull secondary to the fibrous dysplasia.

nerve and progressive visual loss. In such cases, decompression of the optic nerve with or without cranioorbital reconstruction may be indicated. We have reported our experience in two such cases in which we used frameless stereotactic systems and intraoperative image guidance to assist in unroofing the optic canal in the presence of distorted anterior cranial base anatomy. ${ }^{3}$

Although an incidence $(25 \%)$ of recurrence associated with partial removal of the lesion has been reported, ${ }^{59}$ radiotherapy has not been recommended because of the risk of malignant transformation. ${ }^{89}$ Even without radiotherapy, however, there have been reports of spontaneous malignant transformation. ${ }^{126}$

\section{Esthesioneuroblastoma of the Anterior Cranial Fossa}

Esthesioneuroblastomas or olfactory neuroblastomas are tumors of neuroectodermal origin believed to arise from the mitotically active basal layer of the olfactory epithelium normally located within the superior one third of the nasal septum, cribriform plate, and superior turbinates. ${ }^{7}$ Resection alone or in combination with radio- and/ or chemotherapy has been performed in their management. ${ }^{56,61,86}$ Their staging has been performed using the Kadish system ${ }^{61}$ depending on the extent of disease. In Kadish Stage A, the tumor is limited to the nasal cavity; in Stage B, it is localized to the nasal cavity and paranasal sinuses; and in Stage C, it extends beyond the nasal cavity and paranasal sinuses. Five-year survival rates in patients with Stage A, B, and C disease have been reported to be 75,60 , and $41 \%$, respectively. ${ }^{29}$
In a series of 49 patients with esthesioneuroblastoma treated at the Mayo Clinic between 1951 and 1990, pathological grade of the lesion was identified as the most important prognostic factor. ${ }^{86}$ Their clinical manifestations and treatment results were reviewed to identify possible prognostic factors. Whereas the overall 5-year survival rate in all patients was $69 \%$, that in patients with low- and high-grade tumors was 80 and $40 \%$, respectively. Surgery alone was advocated in cases of low-grade tumors if tumor-free margins could be obtained. Radiotherapy was recommended in cases of low-grade tumors when margins are close, in those of residual or recurrent disease, and in those of all high-grade cancers. The addition of chemotherapy was suggested in the management of patients with high-grade tumors.

Chemotherapeutic agents have been mostly used to treat patients with recurrent, metastatic, or inoperable disease. Single chemotherapeutic agents include thiotepa, doxorubicin, cyclophosphamide, vincristine, decarbazine, and nitrogen mustard. ${ }^{56}$ Consistent responses have been demonstrated using combinations including cyclophosphamide with or without vincristine usually when administered every 21 days, toxicity permitting. ${ }^{56}$ Neoadjuvant combination therapies include cyclophosphamide/doxorubicin/vincristine, ${ }^{21}$ cisplatin/VP-1621, and cisplatin and 5 -fluorouracil by continuous infusions daily for 6 days, repeated every 21 days for four cycles, and followed by resection. ${ }^{94}$ An alternating regimen of cyclophosphamide and vincristine with cisplatin and VP-16 every 3 weeks has been used and a good palliative response achieved. 
High-dose chemotherapy combined with autologous bone marrow transplantation has also been used in patients with recurrent disease. ${ }^{93,122}$

\section{NEUROSURGICAL APPROACHES TO THE ANTERIOR CRANIAL BASE}

Surgical approaches to the anterior cranial base include transfacial, anterior craniofacial, craniotomy with orbital and/or zygomatic osteotomy, and transsphenoidal. ${ }^{88,129}$ The transfacial approaches can be categorized into transoral, transpalatal, lateral rhinotomy, Le Fort I osteotomy, and midfacial degloving. ${ }^{72}$ Although these approaches are undertaken in adults, their use in children frequently requires modification. The transoral, and specifically the labial-mandibulotomy approach provides adequate exposure but destroys the pediatric patient's central incisors, and it may jeopardize other tooth buds in patients younger than $6^{72}$ or 10 years of age. ${ }^{68}$ The bulk of soft tissue that must be retracted when performing the transpalatal approach restricts exposure of the upper clival and sphenoidal regions. ${ }^{72}$ The major transpalatal approach- related concerns are the development of a palatal fistula or wound dehiscence. ${ }^{109}$

Lewark, et al., ${ }^{72}$ performed Le Fort I osteotomies in 11 children and reported related complications including loss of unerupted tooth buds and epiphora in one case each. Disruption of facial growth was assumed to be unlikely because the osteotomy did not pass through growth centers. ${ }^{11}$ Although disruption of facial growth has been a source of concern, several groups have reported no such disruption when performing anterior (transzygomatic, orbital, transoral, and transmandibular) and lateral (petrous, transcondylar, translabyrinthine, and transbasal) approaches. ${ }^{68,95,129}$ Although they did not conduct formal morphometric studies on facial bones obtained in children with craniofacial procedures, Teo, et al., ${ }^{129}$ found normal facial skeletal growth in patients as young as 4 years of age in whom 20 months of follow-up data were available.

Midfacial degloving provides good anterior exposure and, when combined with complete ethmoidectomy or medial maxillectomy, can create central skull base exposure $^{72}$ without leaving external facial deformity. With endoscopic assistance, this approach has been performed in infants. ${ }^{134}$ Drawbacks include sensory disturbances involving the teeth and infraorbital nerve distribution, ${ }^{72}$ oroantral fistula, and epiphora..$^{55}$ In the anterior craniofacial approach a conventional bifrontal craniotomy is combined with a transfacial approach, thereby allowing excellent access to tumors of the anterior cranial base and sinuses and nasal cavities. ${ }^{72,129}$

Craniotomy, when combined with the orbital and/or zygomatic osteotomy, provides a lower trajectory approach and allows access to suprasellar and cavernous sinus lesions. ${ }^{117,129}$ In children younger than 6 years of age, the anterior cranial fossa is generally relatively shallow and the frontal sinuses have not developed fully. This makes anterior cranial approaches less difficult in children than in adults. ${ }^{68}$

The transsphenoidal approach has many variations including a sublabial transnasal dissection, perinasal, transethmoid, pure transnasal, and endoscopic. ${ }^{75,129,135}$ Trans- sphenoidal surgery in children may be limited by virtue of the small sella and the absence of a fully aerated sphenoid sinus. In such cases, image guidance may be invaluable for keeping the neurosurgeon directly on the midline when approaching the sella. ${ }^{3}$

\section{TUMORS OF THE MIDDLE CRANIAL BASE IN CHILDREN}

Middle cranial base lesions in children can cause symptoms relating to the central (sphenoid sinus/sella turcica), paracentral (cavernous sinus), or lateral (sphenoid wing/ infratemporal fossa) middle fossa. ${ }^{88}$ Central middle fossa lesions result in pituitary and hypothalamic abnormalities such as panhypopituitarism, precocious puberty, secondary amenorrhea, ${ }^{3}$ and diabetes inspidus, ${ }^{88}$ or they cause deficits secondary to mass effect on the optic nerve and chiasm. ${ }^{88}$ In cases of lesions of the paracentral middle fossa, patients can develop intractable facial pain and dysesthesia, and tumors can affect the optic nerve in the apex, third through sixth cranial nerves, temporal and frontal lobes, and the cavernous carotid artery. ${ }^{88}$ Lateral middle fossa lesions affect the divisions of the trigeminal nerve, lateral orbit, and infratemporal fossa and can cause facial deformity and oropharyngeal obstruction. ${ }^{88}$

In adults, meningiomas and schwannomas of the gasserian ganglion are the most common middle cranial base tumors. ${ }^{76}$ In children astrocytomas, pituitary adenomas, craniopharyngiomas, ${ }^{3}$ hemangiomas, giant cell tumors, malignant fibrous histiocytomas, optic nerve gliomas, osteoblastomas, ${ }^{77}$ and juvenile nasopharyngeal angiofibromas $^{72}$ have been reported. We discuss the craniopharyngiomas and juvenile nasopharyngeal angiofibromas with respect to presentation, surgery, radio-, and chemotherapy.

\section{Craniopharyngioma of the Middle Cranial Base}

Craniopharyngiomas are slow-growing, benign epithelial neoplasms of the sellar region believed to originate from remnants of embryonic squamous cell rests of an incompletely involuted hypophyseal-pharyngeal duct. ${ }^{85} \mathrm{Al}-$ though not strictly a tumor of skull base origin, the frequent use of skull base approaches and the minimal brain retraction required when resecting this tumor justify its inclusion.

Authors of recent series have shown that craniopharyngiomas account for 1.8 to $4.4 \%$ of pediatric brain tumors ${ }^{60,101}$ and occur equally between sexes. ${ }^{85}$ Craniopharyngiomas occur sporadically and generally have no direct pattern of familial inheritance. ${ }^{85}$ No consistent and specific chromosomal abnormalities have been associated with craniopharyngiomas. Children harboring these lesions can present with headaches, visual disturbance, endocrine disorders, and mental disturbance. Compared with adults, children present more often with headache and vomiting due to mass effect or obstructive hydrocephalus than with visual difficulties. ${ }^{87,114}$ In 20 to $30 \%$ of cases children present with visual changes, ${ }^{114}$ which can include decrease in visual acuity, diplopia, blurred vision, bitemporal hemianopia, homonymous hemianopia, various quadrantanopias, central scotomas, see-saw nystagmus, and uni- or even bilateral blindness. ${ }^{85,125}$ A significant relationship between tumor location and clinical presentation has been found; 
authors reported that patients with prechiasmatic tumors presented with more significant losses of visual acuity and field than did those with retrochiasmatic tumors. ${ }^{52}$

Although an endocrine abnormality is found in 80 to $90 \%$ of patients, it is not a frequent cause of medical consultations. ${ }^{85}$ In children medical attention is sought because of short stature and retarded linear growth, whereas in adolescents delayed or arrested puberty is observed. Growth hormone is the most common hormonal deficiency, followed by luteinizing hormone or follicle-stimulating hormone, adrenocorticotropic hormone, and thyroidstimulating hormone. Hyperprolactinemia may be caused by compression of the pituitary stalk or hypothalamus, regions that normally inhibit prolactin release. Diabetes insipidus and the syndrome of inappropriate antidiuretic hormone secretion ${ }^{44,45}$ are also seen in the pediatric population. Although mental disturbance secondary to tumor expansion into the frontal and temporal lobes can occur frequently in adults, it is unusual in children. ${ }^{85}$

Management of these lesions requires multidisciplinary strategies involving neuroophthalmology, endocrinology, neuropsychology, and radiation oncology, as well as neurosurgery. Because visual disturbances frequently occur in patients with craniopharyngiomas, full visual acuity and field examination should be performed prior to any surgical management. Endocrinologists should be involved to correct hormonal deficiencies including diabetes insipidius, hypoadrenalism, and hypothyroidism, which have been shown to increase intra- and postoperative morbidity rates. ${ }^{131}$

There is controversy regarding the optimum surgical management, particularly between subtotal resection combined with postoperative radiotherapy compared with gross-total resection. The location of the tumor dictates the surgical approach. Some of the common surgical approaches include subfrontal, pterional, transsphenoidal, transcallosal, transtemporal, and subtemporal. Proponents of subtotal resection combined with radiotherapy assert that this therapeutic combination decreases tumor recurrence and results in fewer neurological, endocrinological, and psychological deficits compared with aggressive resection. ${ }^{8,33,100}$ Various radiotherapy modalities include external fractionated irradiation, fractionated stereotactic radiotherapy, stereotactic radiosurgery, and stereotactic intracavitary implantation of radionucleotides. ${ }^{85}$ Neurological, vascular, and endocrinological morbidities have been correlated to radiation dosage, ${ }^{100,125}$ with the neurological and vascular deficits reported only in patients who had received a greater than 6100-cGy radiation dose. Because radiotherapy treatment in preschoolers can be hazardous to the developing brain, Kennedy and Haines ${ }^{64}$ have advocated a policy of total or subtotal resection in conjunction with follow-up serial MR imaging and periodic physical examination. Radiation therapy was only initiated in cases of recurrence or symptomatic tumor regrowth at a later date.

Advocates of total resection believe that that the longterm effects of radiotherapy may expose patients to significant risks of secondary endocrinopathy, vasculopathy, and malignant neoplasms..$^{92,131}$ Neurosurgical adjunctive procedures that we have found that aid in the removal of craniopharyngioma via the extended subfrontal approach include a unilateral orbitotomy up to the midline, en bloc removal of the orbital roof, ligation and transection of the anterior superior sagittal sinus, and generous aspiration of CSF from the cisterns and/or release of CSF from an external ventricular drain in cases in which hydrocephalus is present (Fig. 4).

Click here to view Video Clip: Removal of prechiasmatic portion of solid craniopharyngioma.

Radiotherapy is thought to make reresection more difficult, resulting in increased rates of morbidity and mortality in cases of tumor recurrences. ${ }^{137,143}$ At our institution, we found no incidence of recurrence in 17 children who underwent total resection between 1950 and $1989,{ }^{53}$ and a tumor recurrence rate of $29 \%$ in patients who underwent surgery between 1975 and 1989.52 Endocrinopathies are common after gross-total resection; ${ }^{52,67,100,125,132,138,143}$ however, they may be associated with the surgical approach, and the incidence of endocrinopathy is decreased after transsphenoidal or subtotal tumor resection combined with radiotherapy. ${ }^{69,70,100}$ Other surgery-related complications include postoperative drowsiness and a persistent confusional state associated with the transtemporal approach, ${ }^{125}$ fusiform dilation of the internal carotid artery, ${ }^{124}$ fatal intraoperative internal carotid artery rupture associated with transsphenoidal resection, ${ }^{67}$ rhinorrhea or meningitis after drilling of the tuberculum sellae, or transsphenoidal surgery. ${ }^{52,54}$ Ectopic craniopharyngioma has been

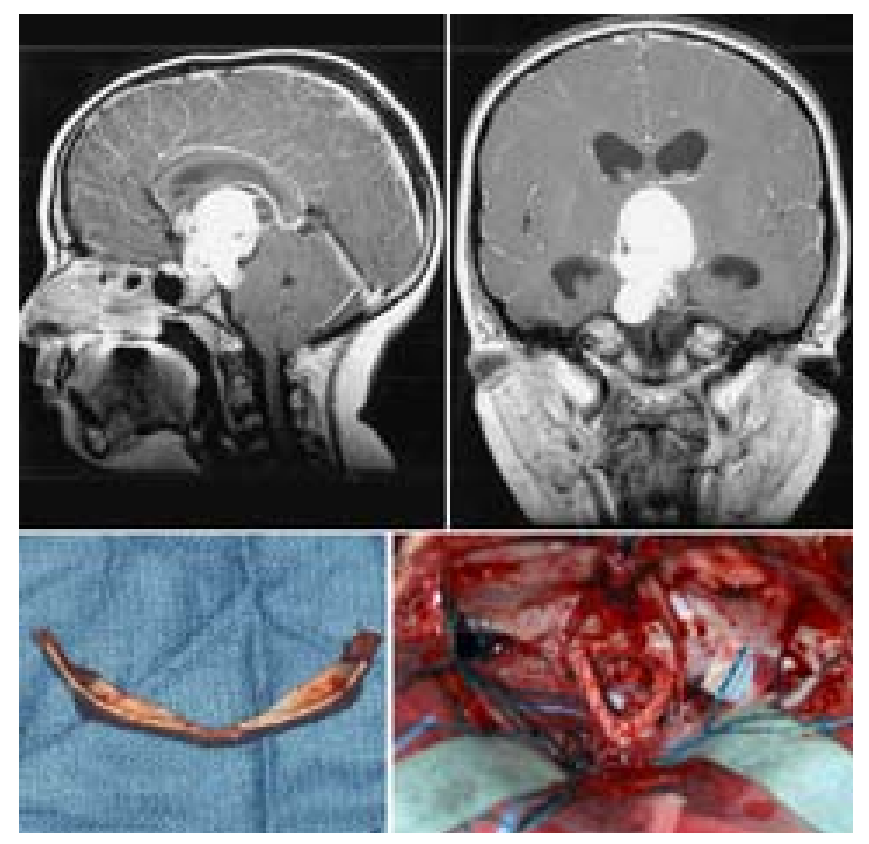

Fig. 4. Upper Left: Sagittal MR image obtained in a 10-yearold girl harboring a giant craniopharyngioma. Upper Right: Coronal MR image obtained in the same patient, demonstrating the vertical extent of the lesion. Lower Left: Photograph showing the excised orbit. An orbitotomy assists with the exposure of the anterior cranial fossa via the subfrontal approach. Lower Right: Intraoperative photograph obtained after the tumor resection, demonstrating the extent of exposure obtained via the subfrontal approach. 
found in cases in which the transcallosal approach has been undertaken. ${ }^{74}$

In cases of cystic craniopharyngiomas, drainage and injection of radioactive isotopes or chemotherapeutic agents, specifically bleomycin, ${ }^{128}$ have been reported. Complications of intralesional chemotherapeutic treatment have been reported to be associated with the toxic effects of bleomycin on the hypothalamus, ${ }^{48}$ as in a case in which, after intracystic injection of bleomycin, a patient developed hypersomnia, personality changes, memory impairment, and thermal dysfunction. Bremer, et al., ${ }^{14}$ have reported finding neurological improvement and decreased cyst size following systemic combination treatment with vincristine, carmustine (BCNU), and procarbazine.

\section{Juvenile Nasopharyngeal Angiofibromas of the Middle Cranial Base}

Juvenile nasopharyngeal angiofibromas are rare, histologically benign, locally invasive tumors ${ }^{57}$ or vascular malformations ${ }^{9}$ of the nasopharynx that are found primarily in the pubescent male. We have recently reported on a 12-year-old boy who harbored paranasal tumor that extended into the cavernous sinus; we performed preoperative embolization and then resected the lesion via a subfrontal transbasal approach, orbitozygomatic osteotomy, lateral rhinotomy, and medial maxillotomy. The boy had presented with facial asymmetry, proptosis, progressive visual failure, and partial progressive oculomotor palsy. He is currently undergoing radiotherapy targeting a small infratemporal residual mass (Fig. 5).

Although usually localized to the nasopharyngeal regions, intracranial invasion can occur in as many as $36 \%$ of cases. ${ }^{57}$ Surgery and radiotherapy are the mainstays of treatment. Because of the increased intra- or postoperative hemorrhage associated with these lesions, preoperative embolization ${ }^{91,118}$ has been used to minimize blood loss. Common postoperative complications include eustachian tube dysfunction, ${ }^{30,47}$ palatal dehiscence, and rhinolalia aperta. $^{28}$

Radiotherapy has been advocated as a primary treatment ${ }^{24,140}$ and as an adjunct to surgery ${ }^{28,46}$ in patients with

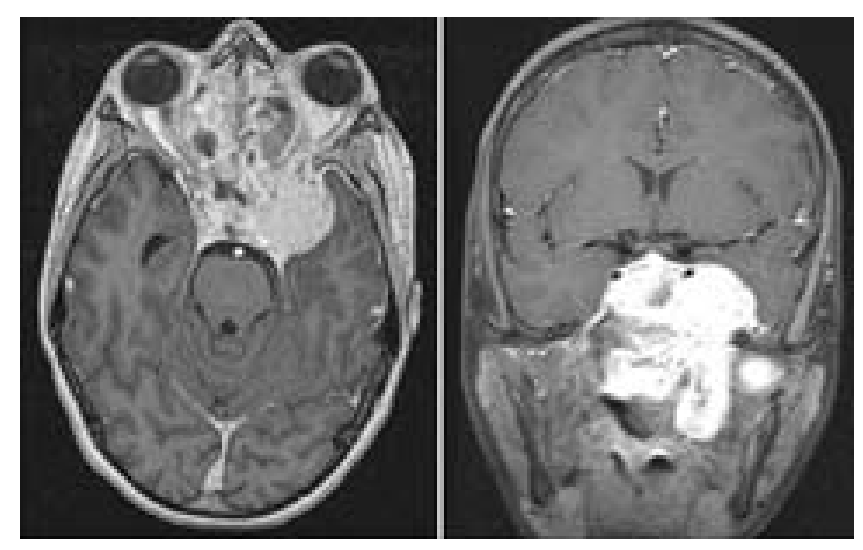

Fig. 5. Left: Axial MR image obtained in a 12-year-old boy with juvenile angiofibroma affecting the middle and anterior cranial skull base compartments. Right: Coronal MR image demonstrating proximity of the lesion to the cavernous sinuses bilaterally. advanced disease. In one study the authors reported longterm results demonstrated in 15 patients who underwent radiotherapy alone, and they found that two developed recurrent disease requiring salvage surgery. ${ }^{99}$ Whereas chemotherapy trials are difficult because of the rarity of the disease, chemotherapeutic agents have been used as adjuncts to surgery. A testosterone receptor blocker, flutamide, has been found to shrink tumors an average of $44 \%$, while allowing patients to retain normal testosterone levels 2 or more years posttherapy. ${ }^{40}$ Other agents associated with varying success include doxorubicin and decarbazine, ${ }^{110}$ doxorubicin, vincristine, dactinomycin, and cyclophosphamide. $^{42}$

\section{NEUROSURGICAL APPROACHES TO THE MIDDLE CRANIAL BASE}

Middle cranial base approaches ${ }^{64,88}$ undertaken in the pediatric population include: 1) frontotemporal with orbital and/or zygomatic osteotomy:71,81 2) temporal with zygomatic osteotomy and/or anterior petrosectomy; ${ }^{19,35,83,119}$ 3 ) preauricular infratemporal with or without mandibular dislocation or resection;,123 and 4) transsphenoidal. ${ }^{45,129}$ Complications reported in association with the first anterolateral approach include death, pneumonia with septicemia, wound infection, meningitis, CSF leakage, cranial nerve palsy, ${ }^{71}$ minimal transient complications (mild trismus, frontal branch paresis, serous effusion, and cheek hypesthesia), ${ }^{15}$ and poor cosmetic result. ${ }^{81}$ The temporal approach in conjunction with petrosectomy was associated with new deterioration of facial nerve function, ${ }^{19}$ subdural temporal lobe hemorrhage, and CSF rhinorrhea. ${ }^{119}$ Complications associated with the infratemporal alone or in conjunction with mandibular manipulations include wound infections, CSF leakage, ${ }^{123}$ temporary restriction of mandibular opening, ${ }^{1}$ conductive hearing loss, numbness of the lower lip, temporal depression caused by the use of the temporalis muscle flap, and facial paresis secondary to translocation of the facial nerve. ${ }^{32,72}$ Because the effect of mandibular resection in the child is not well known, some authors have recommended avoiding mandibular resection whenever possible. ${ }^{64}$ The classic transspenoidal approach involves a sublabial transnasal dissection; however, several modifications have been described involving a perinasal, transethmoid, pure transnasal, microsurgical, or endoscopic technique. ${ }^{26,75,129,135}$ Complications associated with the transsphenoidal technique have already been described.

\section{TUMORS OF THE POSTERIOR CRANIAL BASE IN CHILDREN}

Patients harboring posterior cranial base lesions present with symptoms secondary to the anatomical location within the posterior fossa. ${ }^{88}$ Symptoms of dysphagia or nasal obstruction can occur in cases involving local tumor extension into the retropharynx or nasal cavity, and headaches or neck pain can occur in cases involving the occipital condyle and/or atlantooccipital instability. ${ }^{113}$ Patients most commonly present with headaches or diplopia and are found to have an abducent paresis or palsy. ${ }^{76}$

Although most posterior cranial base tumors such as 
meningioma, ${ }^{4,79}$ schwannoma, ${ }^{43,50,84}$ epidermoid, ${ }^{108,111}$ cholesteatoma, ${ }^{39,97}$ chordoma, ${ }^{13}$ and chondrosarcoma ${ }^{38}$ are more common in adults, other rare tumors such as Ewing sarcoma are more common in children. ${ }^{49}$ We will review the current management strategies associated with cholesteatomas, chordomas and chondrosarcomas, and Ewing sarcoma.

\section{Cholesteatomas of the Posterior Cranial Base}

Cholesteatomas are tumors with a stratified squamous epithelium and keratinous debris derived from the sloughing epithelium ${ }^{82}$ and are categorized as congenital or acquired. Congenital choesteatomas are believed to be secondary to a congenital rest of epithelial tissue trapped in the temporal bone, and acquired cholesteatomas are thought to result from a retraction pocket, otitis media, or abnormal epithelial migration secondary to tympanic membrane perforation. ${ }^{12}$ Because cholesteatomas have been reported to be more invasive in children than adults, some authors have advocated a more aggressive approach in children. ${ }^{12}$

The mainstay for treatment of cholesteatoma is surgery. In both congenital and acquired cholesteatomas, the goal of surgery is complete removal of the squamous epithelium, preservation or restoration of hearing, and maintenance of normal anatomy. ${ }^{36}$ There are two main surgeryrelated strategies in the management of these lesions. One strategy is to perform aggressive exteriorization of the diseased ear and create a common cavity that exists as a "bowl" after the procedure. This procedure, termed the canal-wall-down mastoidectomy, provides better exposure and allows for postoperative surveillance of the disease. $^{34}$ The canal-wall-down directive refers to the removal of the posterior ear canal wall. A second strategy involves removing the cholesteatoma while attempting to preserve middle ear hearing and function. ${ }^{34}$ Because these canal-wall-up procedures have been reported to increase the incidence of recurrent cholesteatomas, ${ }^{133}$ surgeons perform second-look procedures to search for tumor recurrence. ${ }^{136}$ A minimal endoscopic second-look procedure has been reported to be better accepted by patients. ${ }^{130} \mathrm{Be}$ cause the incidence of residual or recurrent disease has been reported to be as high as $57 \%$ after 5 years, ${ }^{105}$ longterm follow-up examination is essential.

Microbial therapy should be topical, but systemic therapy may occasionally be helpful. ${ }^{103}$ There is no accepted medical treatment of cholesteatoma. ${ }^{34}$ Antimetabolites, such as 5-fluorouracil, have been used to inhibit the keratin formation and reduce mucous hypersecretion, and results have been shown to persist even 12 months after suspending treatment. ${ }^{107,142}$ Intratympanic prednisolone has also been found to decrease experimental cholesteatoma production. ${ }^{116}$ Other investigated agents include hyaluronic acid and cyclophosphamide, but no success has been observed. ${ }^{96,139}$

\section{Chordomas and Chondrosarcomas}

The location and surgical treatment of chordomas and chondrosarcomas are similar. ${ }^{113}$ They are typically slowgrowing, locally invasive tumors that occur at the cranial base. ${ }^{64}$ In our experience, chordomas in the young (particularly in females) behave more aggressively with a rela- tively shorter history of symptoms, shorter interval to progression, and a tendency for early development of metastatic disease.

Chordomas are dysontogenetic neoplasms that originate from the embryonic notochord and have the fairly consistent features of an overall lobular arrangement of cells, cells that grow in cords, irregular bands or pseudoacinar form, mucinous matrix, and large physaliphorous and vacuolated cells. ${ }^{106}$ Tending to occur in a paramedian location, chondrosarcomas have been classified as classic, mesenchymal, and dedifferentiated; ${ }^{66}$ the mesenchymal and dedifferentiated types are more aggressive than the classic type. ${ }^{113}$ Children tend to present with atypical chordomas. ${ }^{13}$

Treatment generally consists of an attempt at complete resection (Fig. 6) and postoperative radiotherapy. ${ }^{20,23,127,141}$ These tumors are generally soft and cartilaginous or gelatinous; however, they may also be calcified. ${ }^{113}$ The core of the tumor is resected piecemeal or by using a drill, and the margins are then removed until normal bone or venous channels within the bone are encountered. ${ }^{113}$ The otic capsule, compared with the clivus, remains relatively resistant to tumor invasion. ${ }^{113}$ Ensuring complete removal of the tumor margins is difficult because quick sections of bone are not available. ${ }^{113}$ Complete excision of any intradural extension of tumor is also attempted, taking care to avoid encased vessels, nerves, and the brainstem. ${ }^{113}$ Dural defects are repaired by placing grafts as required. ${ }^{113}$

Radiotherapy has been performed as an adjunct to surgery. ${ }^{20,23,127,141}$ The radiation treatments have included pre${ }^{23}$ or postoperative conventional radiotherapy, ${ }^{2,20}$ as well as postoperative stereotactic proton-photon beam therapy. ${ }^{2,20}$ Compared with chordomas, ${ }^{104}$ chondrosarcomas have been found to respond better to radiotherapy; however, the neurotoxicity associated with the use of radiotherapy in young children must be considered and avoided if possible.

The results of chemotherapy have generally been dis-

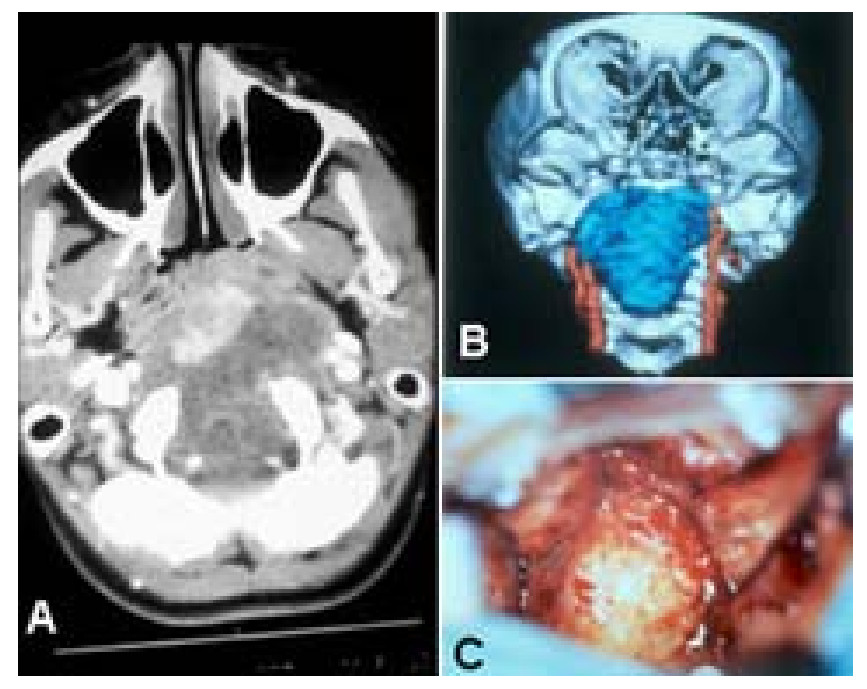

Fig. 6. Left: Axial CT scan obtained in a 14-year-old boy with clival chordoma. Upper Right: Three-dimensional reconstruction of the skull base, demonstrating a massive lesion that has replaced the clivus. Lower Right: Intraoperative photograph obtained during transoral resection of clival chordoma. 
appointing, and this intervention is performed when other therapies have failed. ${ }^{56}$ Symptomatic improvement in some patients has been shown after administration of vincristine, ${ }^{51,98}$ but this agent has failed in combination therapy with others. ${ }^{31,112}$ Single-agent chemotherapy (carboplatin,,$^{37}$ cisplatin, ${ }^{37}$ or methotrexate ${ }^{25}$ ) has been found to be ineffective in terms of tumor response and pain relief. Combination therapies that are associated with varying degrees of success include hydroxyurea with 5-fluorouracil $; 5$ cisplatin, vinblastine, and bleomycin with concurrent radiotherapy $; 6$ preoperative cyclophosphamide, vincristine, doxorubicin, and decarbazine together with radiotherapy: ${ }^{62}$ vincristine and methotrexate with leucovorin rescue $; 7$ and ifosfamide and doxorubicin with intrathecal or intraventricular therapy with hydrocortisone, ara-C, and methotrexate. ${ }^{112}$ No benefit has been reported with the combination of actinomycin-D, cyclophosphamide, and vincristine, nor with cisplatin and 5-fluorouracil or highdose methotrexate. ${ }^{112}$

\section{Ewing Sarcoma}

Ewing sarcoma is a primitive neuroectodermal tumor that can involve the pediatric skull base. It can be massive, and children can present in extremis secondary to mass effect. Currently, the diagnosis of Ewing sarcoma has been facilitated through the use of molecular diagnostic modalities such as spectral karyotyping that have shown a characteristic 11;22 chromosomal translocation. Other molecular studies have shown a frequent EWS/ FLI1 fusion transcript. ${ }^{17}$ Whereas surgery plays a role in decompressing important neural structures at the skull base (Fig. 7), Ewing sarcoma is known to be responsive to aggressive chemotherapeutic agents such as carboplatin, etoposide, and ifosfamide. Radiotherapy is reserved for patients in whom no response to chemotherapy is demonstrated.

\section{NEUROSURGICAL APPROACHES TO THE POSTERIOR CRANIAL BASE}

Posterolateral surgical approaches in the pediatric population can be categorized as transpetrosal, retrosigmoid ${ }^{73,80}$ translabyrinthine ${ }^{68}$ retrolabyrinthine, ${ }^{65}$ and partial labyrinthectomy, ${ }^{115}$ transcochlear, ${ }^{41,90,120}$ far-lateral/extreme-lateral transcondylar, ${ }^{10,64}$ and extreme-lateral, transjugular. ${ }^{63,18,88}$

Like the anterior sinuses, the mastoid air cells are also immature and less fully developed. The solid bone makes both identification of the labyrinth and drilling more difficult and requires the expertise of a neurootologist. The available exposure to the lateral posterior fossa, however, requires less retraction of the neural structures in children than adults. ${ }^{6}{ }^{6}$ Frequent approach-related complications include cranial nerve deficits and CSF leaks. ${ }^{115}$ The retrosigmoid and translabyrinthine techniques can preserve facial nerve function in children, although CSF leakage has also been reported in pediatric series ${ }^{68}$ The transcochlear approach allows access to lesions anteromedial to the internal auditory meatus that are equally distributed within both the middle and posterior cranial fossae. ${ }^{129} \mathrm{It}$ offers only limited exposure to the lateral aspect of the clivus. $^{72}$ Facial nerve deficits may occur ${ }^{90}$ because this approach requires facial nerve transposition. The ap- proach also involves drilling of the temporal bone, including the entire labyrinth, and thus, if hearing requires preservation, the transcochlear approach is inappropriate. ${ }^{129}$

At our institution an infralabyrinthine, infracochlear hearing-sparing approach was recently performed for the drainage and permanent aeration of a cholesterol granuloma of the petrous apex. The lesion occurred in a 16year-old young woman with normal hearing who presented with headaches, progressive diplopia secondary to an abducent palsy, and facial asymmetry (Fig. 8). Postoperatively her cranial nerve deficits and headaches resolved, and hearing remains intact.

The transcondylar approach allows access to lower clival lesions, foramen magnum, and the upper cervical spine. In such cases the sigmoid sinus and jugular bulb will be exposed, and a C-1 laminectomy is continued to expose the vertebral artery. Once the vertebral artery is mobilized, the ipsilateral occipital condyle is resected, as is the lateral process of C-1 or C-2 if necessary. The transjugular approach involves lateral suboccipital craniotomy and resection of the posterior one-third of the occipital condyle. The jugular foramen is opened by removing the posterior wall, without performing a mastoidectomy, to preserve hearing and facial nerve function. ${ }^{63}$

\section{COMPLICATIONS AND OUTCOMES}

Because few series of skull base procedures performed purely in pediatric populations have been reported, it is necessary to extrapolate the complications reported in the adult or mixed populations to the pediatric population. The complications associated with adult or mixed populations will not be reviewed in this paper; rather, we note some of the complications that have been described in pediatric skull base series. ${ }^{3,68,129}$

In a study published by Alshail, et al., ${ }^{3} 13$ children with skull base lesions underwent various neurosurgical procedures including the following: transsphenoidal, pterional, frontal, transoral, subtemporal bifrontal, bifrontal midfacial, and transnasal approaches. ${ }^{3}$ They reported several transient but no permanent neurological deficits. Lewark, et al., ${ }^{72}$ reported on 11 patients (mean age 14.3 years) who underwent a Le Fort I osteotomy in the treatment of the following angiofibromas (eight cases), hemangioma, giant cell tumor, and malignant fibrous histiocytoma (one case each). Complications that occurred in a mean follow-up period of 2.5 years (range 6 months- 2.5 years), included loss of tooth buds, mild enophthalmos, and epiphora. They observed that disruption of facial growth is unlikely, because the osteotomy does not pass through growth centers.

In the large pediatric series reported by Lang, et al. ${ }^{68}$ the authors discuss the results in 20 children (age range 3 months-14 years) harboring the following lesions: arteriovenous malformation, juvenile nasopharyngeal angiofibroma, capillary hemangioma, craniopharyngioma, exophytic brainstem glioma, acoustic schwannoma, hypoglossal and posterior inferior cerebellar artery aneurysm, cranial fasciitis, optic nerve glioma, clivus chordoma, intraorbital cavernoma, craniocervical instability caused by peg migration, epithelioid hemangioendothelioma, optic sheath meningioma, and meningioma. Surgical procedures included transzygomatic, translabyrinthine, cranio- 
Skull base tumors in children

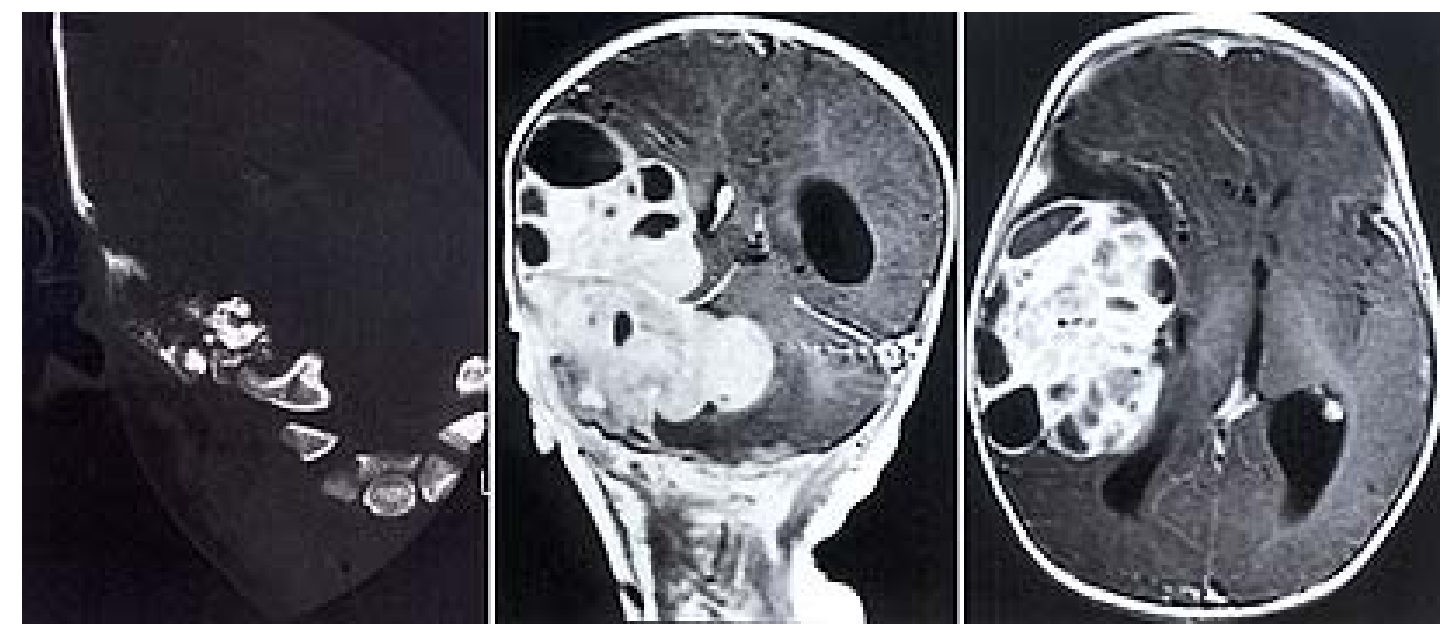

Fig. 7. Lower: Coronal CT scan obtained in an infant with massive skull base Ewing sarcoma. The lesion arises from the petrous bone. Coronal (center) and axial (right) MR images obtained in the same infant, revealing a tumor occupying the middle and posterior cranial fossae. Following tumor decompression, the lesion was treated with aggressive adjuvant chemotherapy, and the child is tumor free and well now 10 years after diagnosis.

facial, transbasal, superior orbitotomy, transcondylar/suboccipital, Le Fort I maxillotomy, orbitozygomatic, transoral, transpetrous, and transmandibular and transzygomatic approaches. Postoperative complications included hypertrophic preauricular scar, temporal hollowing, nasal obstruction, ptosis, visual field defect, visual failure, facial nerve palsy, subarachnoid hemorrhage, diabetes insipidus, CSF leakage, meningitis, and hydrocephalus. No disruption in facial growth was noted in patients orbital or transmandibular access was created; no temporomandibular joint dysfunction was observed in those who underwent surgery via a transzygomatic approach. Based on the indices of the Glasgow Outcome Scale, ${ }^{58}$ good recovery was demonstrated in 18 cases, moderate disability occurred in one, and severe disability was documented in one case. In terms of overall neurological condition, 14 improved, five were unchanged, and one was worse.

In another large series, Teo, et al., ${ }^{129}$ retrospectively reviewed 26 patients (mean age 10.5 years, range 4-20 years) who underwent skull base surgery for various tu-

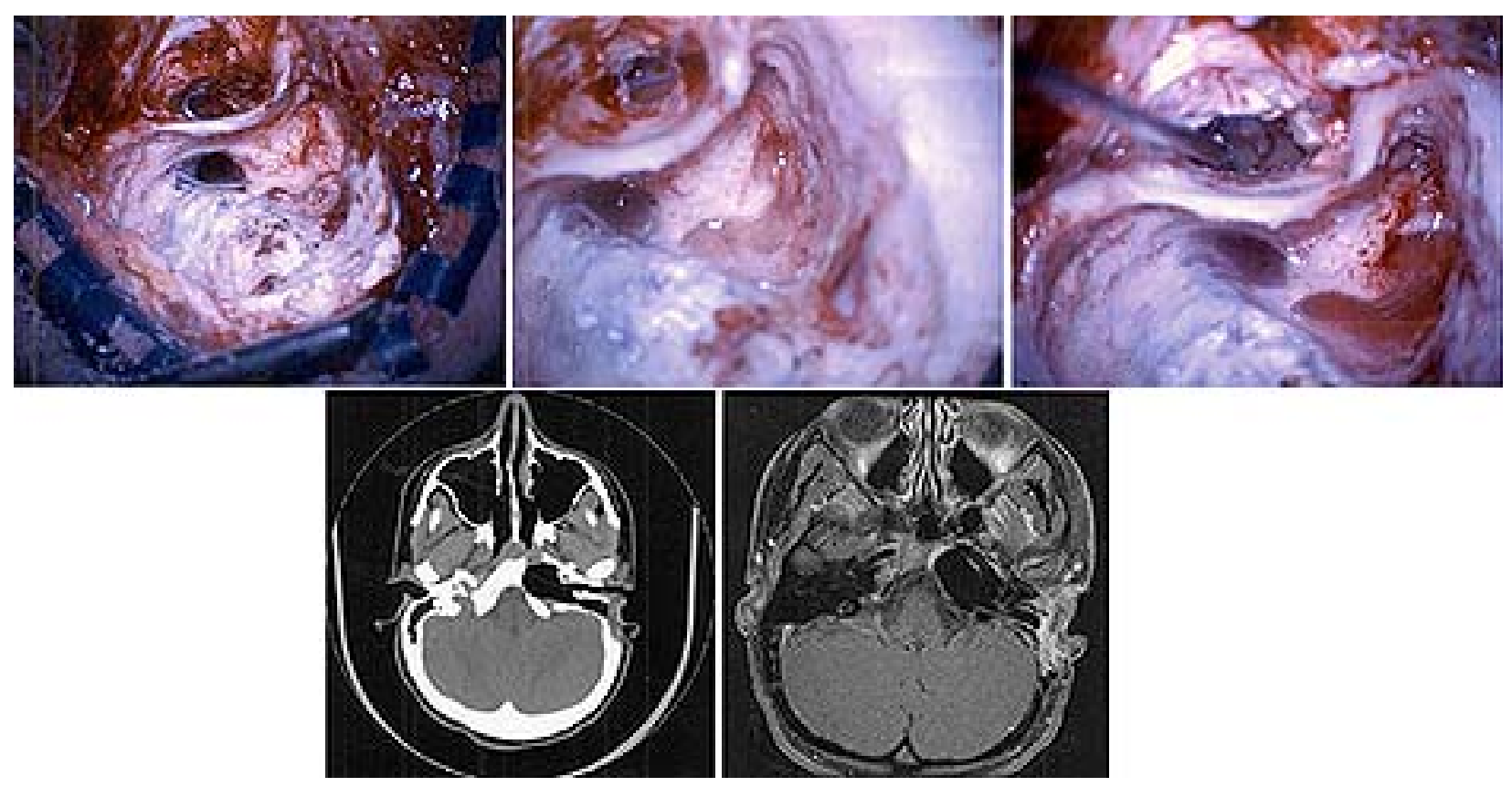

Fig. 8. Upper: Intraoperative photographs of the infralabyrinthine and infratrochlear windows obtained during drainage of the cholesterol granuloma cyst and following insertion of silastic drainage tube for permanent aeration. Lower: Postoperative axial CT scan, and axial and coronal $\mathrm{T}_{1}$-weighted MR images demonstrating drainage and aeration of the cholesterol granuloma cyst. 


\section{E. C. Tsai, S. Santoreneos, and J. T. Rutka}

mor types including schwannoma, chordoma, fibrous dysplasia, plexiform neurofibroma, ependymoma, and esthesioneuroblastoma. Surgery was performed using anterior craniofacial, cranioorbitozygomatic, transsphenoidal, transpetrosal, retrosigmoid, transcochlear, and transcondylar approaches. There were five deaths, three of which were caused by the primary disease, one of aspiration pneumonia secondary to surgery-induced cranial nerve deficits, and one of fulminant diabetes insipidus. The rate of immediate postoperative complications was 57\%, not including "expected deficits" such as deafness in patients with large acoustic tumors and in whom there was no functional hearing preoperatively. These complications included: facial nerve palsy or paresis, ninth, 10, and 11th cranial nerve palsies, aspiration pneumonia, dysphagia, dysphonia, facial anesthesia, panhypopituitarism, CSF leakage, meningitis, and memory disturbance. Permanent complications were only slightly lower at $30.7 \%$, and these included facial palsy or paresis, dysphagia, hydrocephalus, quadriparesis, dysphonia, panhypopituitarism and corneal ulceration, and blindness. In $27 \%$ of the patients there were no expected deficits or postoperative complications; in an additional 15\% there were expected deficits but no complications. The authors also noted no disruption in facial growth.

Teo, et al., ${ }^{129}$ allocated their patients into outcome categories of good (complete tumor resection with acceptable postoperative deficits), fair (complete tumor resection with significant postoperative deficits that did not affect the patient's function), and poor (unacceptable postoperative deficits that affected the patient's function). Overall, they attributed one death to be a direct result of surgery. Overall good, fair, and poor outcomes were reported in 62, 15 , and $4 \%$, respectively. The 2 -year tumor-free survival rate was $81 \%$.

\section{CONCLUSIONS}

Tumors of the skull base in pediatric patients pose unique challenges to the neurosurgeon. The differential diagnosis of a skull base tumor in this population differs from that in the adult population. With a working knowledge of skull base anatomy, as well as special considerations given to the developing craniofacial skeleton, skull base lesions can be treated in children and the related morbidity and mortality rates can be acceptable. Outcomes in children with skull base tumors may be better than those in adults, in part because of the benign histopathology that frequently affects the pediatric skull bass as well as the plasticity of the developing nervous system.

\section{References}

1. Al-Mefty O, Anand VK: Zygomatic approach to skull-base lesions. J Neurosurg 73:668-673, 1990

2. Al-Mefty O, Borba LA: Skull base chordomas: a management challenge. J Neurosurg 86:182-189, 1997

3. Alshail E, Rutka JT, Drake JM, et al: Utility of frameless stereotaxy in the resection of skull base and basal cerebral lesions in children. Skull Base Surg 8:29-38, 1998

4. Amirjamshidi A, Mehrazin M, Abbassioun K: Meningiomas of the central nervous system occurring below the age of 17: report of 24 cases not associated with neurofibromatosis and review of literature. Childs Nerv Syst 16:406-416, 2000
5. Ariel IM, Verdu C: Chordoma: an analysis of twenty cases treated over a twenty-year span. J Surg Oncol 7:27-44, 1975

6. Azzarelli A, Quagliuolo V, Cerasoli S, et al: Chordoma: natural history and treatment results in 33 cases. J Surg Oncol 37:185-191, 1988

7. Barnes L, Kapadia SB: The biology and pathology of selected skull base tumors. J Neurooncol 20:213-240, 1994

8. Baskin DS, Wilson CB: Surgical management of craniopharyngiomas. A review of 74 cases. J Neurosurg 65:22-27, 1986

9. Beham A, Beham-Schmid C, Regauer S, et al: Nasopharyngeal angiofibroma: true neoplasm or vascular malformation? Adv Anat Pathol 7:36-46, 2000

10. Bejjani GK, Sekhar LN, Riedel CJ: Occipitocervical fusion following the extreme lateral transcondylar approach. Surg Neurol 54:109-116, 2000

11. Belmont JR: The Le Fort I osteotomy approach for nasopharyngeal and nasal fossa tumors. Arch Otolaryngol Head Neck Surg 114:751-754, 1988

12. Bluestone CD, Klein JO: Intratemporal complications and sequelae of otitis media, in Bluestone CD, Stool SE, Kenna MA (eds): Pediatric Otolaryngology, ed 3. Philadelphia: WB Saunders, 1996, Vol 1, pp 604-635

13. Borba LA, Al-Mefty O, Mrak RE, et al: Cranial chordomas in children and adolescents. J Neurosurg 84:584-591, 1996

14. Bremer AM, Nguyen TQ, Balsys R: Therapeutic benefits of combination chemotherapy with vincristine, $\mathrm{BCNU}$, and procarbazine on recurrent cystic craniopharyngioma. A case report. J Neurooncol 2:47-51, 1984

15. Browne JD, Jacob SL: Temporal approach for resection of juvenile nasopharyngeal angiofibromas. Laryngoscope 110: 1287-1293, 2000

16. Camilleri AE: Craniofacial fibrous dysplasia. J Laryngol Otol 105:662-666, 1991

17. Carlotti CG Jr, Drake JM, Hladky JP, et al: Primary Ewing's sarcoma of the skull in children. Utility of molecular diagnostics, surgery and adjuvant therapies. Pediatr Neurosurg 31: 307-315, 1999

18. Cass SP, Hirsch BE, Stechison MT: Evolution and advances of the lateral surgical approaches to cranial base neoplasms. J Neurooncol 20:337-361, 1994

19. Cass SP, Sekhar LN, Pomeranz S, et al: Excision of petroclival tumors by a total petrosectomy approach. Am J Otol 15: 474-484, 1994

20. Catton C, O'Sullivan B, Bell R, et al: Chordoma: long-term follow-up after radical photon irradiation. Radiother Oncol 41:67-72, 1996

21. Chao KS, Kaplan C, Simpson JR, et al: Esthesioneuroblastoma: the impact of treatment modality. Head Neck 23: 749-757, 2001

22. Coffin CM, Swanson PE, Wick MR, et al: Chordoma in childhood and adolescence. A clinicopathologic analysis of 12 cases. Arch Pathol Lab Med 117:927-933, 1993

23. Crockard A, Macaulay E, Plowman PN: Stereotactic radiosurgery. VI. Posterior displacement of the brainstem facilitates safer high dose radiosurgery for clival chordoma. Br J Neurosurg 13:65-70, 1999

24. Cummings BJ, Blend R, Keane T, et al: Primary radiation therapy for juvenile nasopharyngeal angiofibroma. Laryngoscope 94:1599-1605, 1984

25. Cummings BJ, Esses S, Harwood AR: The treatment of chordomas. Cancer Treat Rev 9:299-311, 1982

26. de Divitiis E, Cappabianca P, Gangemi M, et al: The role of the endoscopic transsphenoidal approach in pediatric neurosurgery. Childs Nerv Syst 16:692-696, 2000

27. Di Rocco C, Marchese E, Velardi F: Fibrous dysplasia of the skull in children. Pediatr Neurosurg 18:117-126, 1992

28. Economou TS, Abemayor E, Ward PH: Juvenile nasopharyngeal angiofibroma: an update of the UCLA experience, 1960-1985. Laryngoscope 98:170-175, 1988 
29. Elkon D, Hightower SI, Lim ML, et al: Esthesioneuroblastoma. Cancer 44:1087-1094, 1979

30. Fagan JJ, Snyderman CH, Carrau RL, et al: Nasopharyngeal angiofibromas: selecting a surgical approach. Head Neck 19: 391-399, 1997

31. Ferry AP, Haddad HM, Goldman JL: Orbital invasion by an intracranial chordoma. Am J Ophthalmol 92:7-12, 1981

32. Fisch U, Pillsbury HC: Infratemporal fossa approach to lesions in the temporal bone and base of the skull. Arch Otolaryngol 105:99-107, 1979

33. Fischer EG, Welch K, Shillito J Jr, et al: Craniopharyngiomas in children. Long-term effects of conservative surgical procedures combined with radiation therapy. J Neurosurg 73: 534-540, 1990

34. Forsen JW: Chronic disorders of the middle ear and mastoid, in Wetmore RF, Muntz HR, McGill TJ (eds): Pediatric Otolaryngology: Principles and Practice Pathways. New York: Thieme, 2000, pp 293-303

35. Fournier H, Mercier P: A limited anterior petrosectomy with preoperative embolization of the inferior petrosal sinus for ventral brainstem tumor removal. Surg Neurol 54:10-18, 2000

36. Fucci MJ: Skull base, petrous apex, tumors. eMedicine J 2 (7):2001

37. Fuller DB, Bloom JG: Radiotherapy for chordoma. Int J Radiat Oncol Biol Phys 15:331-339, 1988

38. Gadwal SR, Fanburg-Smith JC, Gannon FH, et al: Primary chondrosarcoma of the head and neck in pediatric patients: a clinicopathologic study of 14 cases with a review of the literature. Cancer 88:2181-2188, 2000

39. Garap JP, Dubey SP: Canal-down mastoidectomy: experience in 81 cases. Otol Neurotol 22:451-456, 2001

40. Gates GA, Rice DH, Koopmann CF Jr, et al: Flutamide-induced regression of angiofibroma. Laryngoscope 102: 641-644, 1992

41. Glasscock ME III, Woods CI III, Poe DS, et al: Petrous apex cholesteatoma. Otolaryngol Clin North Am 22:981-1002, 1989

42. Goepfert H, Cangir A, Lee YY: Chemotherapy for aggressive juvenile nasopharyngeal angiofibroma. Arch Otolaryngol 111:285-289, 1985

43. Gonzales-Pardo L, Brackett CE, Lansky LL: Facial nerve schwannoma in a 16-year-old girl. Childs Brain 7:220-224, 1980

44. Gonzales-Portillo G, Tomita T: The syndrome of inappropriate secretion of antidiuretic hormone: an unusual presentation for childhood craniopharyngioma: report of three cases. Neurosurgery 42:917-922, 1998

45. Gsponer J, De Tribolet N, Deruaz JP, et al: Diagnosis, treatment, and outcome of pituitary tumors and other abnormal intrasellar masses. Retrospective analysis of 353 patients. Medicine 78:236-269, 1999

46. Gullane PJ, Davidson J, O'Dwyer T, et al: Juvenile angiofibroma: a review of the literature and a case series report. Laryngoscope 102:928-933, 1992

47. Haines SJ, Duvall AJ III: Transzygomatic and transpalatal excision of juvenile nasopharyngeal angiofibroma with intracranial extension: the surgical procedure, in Sekhar LN, Janecka IP (eds): Surgery of Cranial Base Tumors. New York: Raven Press, 1993, pp 477-484

48. Haisa T, Ueki K, Yoshida S: Toxic effects of bleomycin on the hypothalamus following its administration into a cystic craniopharyngioma. Br J Neurosurg 8:747-750, 1994

49. Hamilton HB, Voorhies RM: Tumors of the skull, in Wilkins RH, Rengachary SS (eds): Neurosurgery, ed 2. New York: McGraw-Hill, 1996, Vol 2, pp 1503-1528

50. Harada K, Nishizaki T, Adachi N, et al: Pediatric acoustic schwannoma showing rapid regrowth with high proliferative activity. Childs Nerv Syst 16:134-137, 2000
51. Harwick RD, Miller AS: Craniocervical chordomas. Am J Surg 138:512-516, 1979

52. Hoffman HJ, De Silva M, Humphreys RP, et al: Aggressive surgical management of craniopharyngiomas in children. $\mathbf{J}$ Neurosurg 76:47-52, 1992

53. Hoffman HJ, Hendrick EB, Humphreys RP, et al: Management of craniopharyngioma in children. J Neurosurg 47: 218-227, 1977

54. Honegger J, Buchfelder M, Fahlbusch R, et al: Transsphenoidal microsurgery for craniopharyngioma. Surg Neurol 37: 189-196, 1992

55. Howard DJ, Lund VJ: The role of midfacial degloving in modern rhinological practice. J Laryngol Otol 113:885-887, 1999

56. Jacob HE: Chemotherapy for cranial base tumors. J Neurooncol 20:327-335, 1994

57. Jafek BW, Krekorian EA, Kirsch WM, et al: Juvenile nasopharyngeal angiofibroma: management of intracranial extension. Head Neck Surg 2:119-128, 1979

58. Jennett B, Bond M: Assessment of outcome after severe brain damage. Lancet 1:480-484, 1975

59. Jones NF, Schramm VL, Sekhar LN: Reconstruction of the cranial base following tumor resection. Br J Plast Surg 40: 155-162, 1987

60. Kaatsch P, Rickert CH, Kuhl J, et al: Population-based epidemiologic data on brain tumors in German children. Cancer 92:3155-3164, 2001

61. Kadish S, Goodman M, Wang CC: Olfactory neuroblastoma. A clinical analysis of 17 cases. Cancer 37:1571-1576, 1976

62. Karakousis CP, Park JJ, Fleminger R, et al: Chordomas: diagnosis and management. Am Surg 47:497-501, 1981

63. Kawahara N, Sasaki T, Nibu K, et al: Dumbbell type jugular foramen meningioma extending both into the posterior cranial fossa and into the parapharyngeal space: report of 2 cases with vascular reconstruction. Acta Neurochir 140:323-331, 1998

64. Kennedy JD, Haines SJ: Review of skull base surgery approaches: with special reference to pediatric patients. J Neurooncol 20:291-312, 1994

65. Kirazli T, Oner K, Ovul L, et al: Petrosal presigmoid approach to the petro-clival and anterior cerebellopontine region (extended retrolabyrinthine, transtentorial approach). Rev Laryngol Otol Rhinol 122:187-190, 2001

66. Kristensen IB, Sunde LM, Jensen OM: Chondrosarcoma. Increasing grade of malignancy in local recurrence. Acta Pathol Microbiol Immunol Scand [A] 94:73-77, 1986

67. Landolt AM, Zachmann M: Results of transsphenoidal extirpation of craniopharyngiomas and Rathke's cysts. Neurosurgery 28:410-415, 1991

68. Lang DA, Neil-Dwyer G, Evans BT, et al: Craniofacial access in children. Acta Neurochir 140:33-40, 1998

69. Laws ER Jr: Transsphenoidal microsurgery in the management of craniopharyngioma. J Neurosurg 52:661-666, 1980

70. Laws ER Jr: Transsphenoidal removal of craniopharyngioma Pediatr Neurosurg 21 (Suppl 1):57-63, 1994

71. Lee JP, Tsai MS, Chen YR: Orbitozygomatic infratempora approach to lateral skull base tumors. Acta Neurol Scand 87: 403-409, 1993

72. Lewark TM, Allen GC, Chowdhury K, et al: Le Fort I osteotomy and skull base tumors: a pediatric experience. Arch Otolaryngol Head Neck Surg 126:1004-1008, 2000

73. Lippman CR, Jallo GI, Feghali JG, et al: Aneurysmal bone cyst of the temporal bone. Pediatr Neurosurg 31:219-223, 1999

74. Liu JM, Garonzik IM, Eberhart CG, et al: Ectopic recurrence of craniopharyngioma after an interhemispheric transcallosal approach: case report. Neurosurgery 50:639-645, 2002

75. Locatelli D, Castelnuovo P, Santi L, et al: Endoscopic approaches to the cranial base: perspectives and realities. Childs Nerv Syst 16:686-691, 2000 


\section{E. C. Tsai, S. Santoreneos, and J. T. Rutka}

76. Long DM: Surgical approaches to tumors of the skull base: an overview, in Wilkins RH, Rengachary SS (eds): Neurosurgery, ed 2. New York: McGraw-Hill, 1996, Vol 2, pp $1573-1584$

77. Low Y, Foo CL, Seow WT: Childhood temporal bone osteoblastoma: a case report. J Pediatr Surg 35:1127-1129, 2000

78. Macfarlane R, Rutka JT, Armstrong D, et al: Encephaloceles of the anterior cranial fossa. Pediatr Neurosurg 23:148-158, 1995

79. Mandai K, Tamaki N, Kurata H, et al: [The clinical analysis of pediatric meningioma: 5 cases.] No Shinkei Geka 25: 131-136, 1997 (Jpn)

80. Mazzoni A, Calabrese V, Danesi G: A modified retrosigmoid approach for direct exposure of the fundus of the internal auditory canal for hearing preservation in acoustic neuroma surgery. Am J Otol 21:98-109, 2000

81. McDermott MW, Durity FA, Rootman J, et al: Combined frontotemporal-orbitozygomatic approach for tumors of the sphenoid wing and orbit. Neurosurgery 26:107-116, 1990

82. McLendon RE: Epidermoid and dermoid tumors: pathology, in Wilkins RH, Rengachary SS (eds): Neurosurgery, ed 2. New York: McGraw-Hill, 1996, Vol 1, pp 959-964

83. Megerian CA, Chiocca EA, McKenna MJ, et al: The subtemporal-transpetrous approach for excision of petroclival tumors. Am J Otol 17:773-779, 1996

84. Mendel RC, Brumback RA, Leech RW, et al: Pediatric eighth cranial nerve schwannoma without evidence of neurofibromatosis. J Child Neurol 14:67-69, 1999

85. Moore KD, Couldwell WT: Craniopharyngioma, in Bernstein M, Berger MS (eds): Neuro-Oncology: The Essentials. New York: Thieme Medical Publishers, 2000, pp 409-418

86. Morita A, Ebersold MJ, Olsen KD, et al: Esthesioneuroblastoma: prognosis and management. Neurosurgery 32: 706-715, 1993

87. Morita A, Piepgras DG: Tumors of the skull base, in Vecht CJ (ed): Handbook of Clinical Neurology. Amsterdam: Elsevier Science, 1997, pp 465-496

88. Morita A, Sekhar LN: Skull base tumors, in Bernstein M, Berger MS (eds): Neuro-Oncology: The Essentials. New York: Thieme Medical Publishers, 2000, pp 419-433

89. Mortensen A, Bojsen-Moller M, Rasmussen P: Fibrous dysplasia of the skull with acromegaly and sarcomatous transformation. Two cases with a review of the literature. J Neurooncol 7:25-29, 1989

90. Mortini P, Mandelli C, Franzin A, et al: Surgical excision of clival tumors via the enlarged transcochlear approach. Indications and results. J Neurosurg Sci 45:127-140, 2001

91. Moulin G, Chagnaud C, Gras R, et al: Juvenile nasopharyngeal angiofibroma: comparison of blood loss during removal in embolized group versus nonembolized group. Cardiovasc Intervent Radiol 18:158-161, 1995

92. Nelson GA, Bastian FO, Schlitt M, et al: Malignant transformation in craniopharyngioma. Neurosurgery 22:427-429, 1988

93. O'Conor GT Jr, Drake CR, Johns ME, et al: Treatment of advanced esthesioneuroblastoma with high-dose chemotherapy and autologous bone marrow transplantation. A case report. Cancer 55:347-349, 1985

94. Polonowski JM, Brasnu D, Roux FX, et al: Esthesioneuroblastoma. Complete tumor response after induction chemotherapy. Ear Nose Throat J 69:743-746, 1990

95. Posnick JC, Goldstein JA, Armstrong D, et al: Reconstruction of skull defects in children and adolescents by the use of fixed cranial bone grafts: long-term results. Neurosurgery 32: 785-791, 1993

96. Pownell PH, Wright CG, Robinson KS, et al: The effect of cyclophosphamide on development of experimental cholesteatoma. Arch Otolaryngol Head Neck Surg 120:1114-1116, 1994
97. Prescott CA: Cholesteatoma in children-the experience at The Red Cross War Memorial Children's Hospital in South Africa 1988-1996. Int J Pediatr Otorhinolaryngol 49: $15-19,1999$

98. Razis DV, Tsatsaronis A, Kyriazides I, et al: Chordoma of the cervical spine treated with vincristine sulfate. J Med 5: 274-277, 1974

99. Reddy KA, Mendenhall WM, Amdur RJ, et al: Long-term results of radiation therapy for juvenile nasopharyngeal angiofibroma. Am J Otolaryngol 22:172-175, 2001

100. Regine WF, Kramer S: Pediatric craniopharyngiomas: long term results of combined treatment with surgery and radiation. Int J Radiat Oncol Biol Phys 24:611-617, 1992

101. Rickert CH, Paulus W: Epidemiology of central nervous system tumors in childhood and adolescence based on the new WHO classification. Childs Nerv Syst 17:503-511, 2001

102. Rickert CH, Scheithauer BW, Paulus W: Chromosomal aberrations in pituitary carcinoma metastases. Acta Neuropathol 102:117-120, 2001

103. Roland PS: Middle ear, cholesteatoma. eMedicine J 2 (7): 2001

104. Rosenberg AE, Nielsen GP, Keel SB, et al: Chondrosarcoma of the base of the skull: a clinicopathologic study of 200 cases with emphasis on its distinction from chordoma. Am J Surg Pathol 23:1370-1378, 1999

105. Rosenfeld RM, Moura RL, Bluestone CD: Predictors of residual-recurrent cholesteatoma in children. Arch Otolaryngol Head Neck Surg 118:384-391, 1992

106. Ross DA, Sasaki CT: Pathology of tumors of the cranial base. Clin Plast Surg 22:407-416, 1995

107. Sala DT: Topical applications of 5-fluorouracil in the medical treatment of cholesteatoma of the middle ear. Ear Nose Throat J 73:412-414, 1994

108. Salazar J, Vaquero J, Saucedo G, et al: Posterior fossa epidermoid cysts. Acta Neurochir 85:34-39, 1987

109. Sasaki CT, Lowlicht RA, Astrachan DI, et al: Le Fort I osteotomy approach to the skull base. Laryngoscope 100: 1073-1076, 1990

110. Schick B, Kahle G, Hassler R, et al: [Chemotherapy of juvenile angiofibroma-an alternative?] HNO 44:148-152, 1996 (Ger)

111. Schijman E, Monges J, Cragnaz R: Congenital dermal sinuses, dermoid and epidermoid cysts of the posterior fossa. Childs Nerv Syst 2:83-89, 1986

112. Scimeca PG, James-Herry AG, Black KS, et al: Chemotherapeutic treatment of malignant chordoma in children. J Pediatr Hematol Oncol 18:237-240, 1996

113. Sekhar LN, Gay E, Wright DC: Chordomas and chondrosarcomas of the cranial base, in Wilkins RH, Rengachary SS (eds): Neurosurgery, ed 2. New York: McGraw-Hill, 1996, Vol 2, pp 1529-1544

114. Sekhar LN, Moller AR: Operative management of tumors involving the cavernous sinus. J Neurosurg 64:879-889, 1986

115. Sekhar LN, Schessel DA, Bucur SD, et al: Partial labyrinthectomy petrous apicectomy approach to neoplastic and vascular lesions of the petroclival area. Neurosurgery 44:537-552, 1999

116. Sennaroglu L, Ozkul A, Gedikoglu G, et al: Effect of intratympanic steroid application on the development of experimental cholesteatoma. Laryngoscope 108:543-547, 1998

117. Sindou M, Emery E, Acevedo G, et al: Respective indications for orbital rim, zygomatic arch and orbito-zygomatic osteotomies in the surgical approach to central skull base lesions. Critical, retrospective review in 146 cases. Acta Neurochir 143:967-975, 2001

118. Siniluoto TM, Luotonen JP, Tikkakoski TA, et al: Value of pre-operative embolization in surgery for nasopharyngeal angiofibroma. J Laryngol Otol 107:514-521, 1993 
119. Slater PW, Welling DB, Goodman JH, et al: Middle fossa transpetrosal approach for petroclival and brainstem tumors. Laryngoscope 108:1408-1412, 1998

120. Spetzler RF, Daspit CP, Pappas CT: The combined supra- and infratentorial approach for lesions of the petrous and clival regions: experience with 46 cases. J Neurosurg 76:588-599, 1992

121. Stevenson RE, Allen WP, Pai GS, et al: Decline in prevalence of neural tube defects in a high-risk region of the United States. Pediatrics 106:677-683, 2000

122. Stewart FM, Lazarus HM, Levine PA, et al: High-dose chemotherapy and autologous marrow transplantation for esthesioneuroblastoma and sinonasal undifferentiated carcinoma. Am J Clin Oncol 12:217-221, 1989

123. Suarez C, Garcia LA, Fernandez de Leon R, et al: Infratemporal approaches to nasopharyngeal tumors. Eur Arch Otorhinolaryngol 254 (Suppl 1):S165-S168, 1997

124. Sutton LN, Gusnard D, Bruce DA, et al: Fusiform dilatations of the carotid artery following radical surgery of childhood craniopharyngiomas. J Neurosurg 74:695-700, 1991

125. Symon L, Pell MF, Habib AH: Radical excision of craniopharyngioma by the temporal route: a review of 50 patients. Br J Neurosurg 5:539-549, 1991

126. Taconis WK: Osteosarcoma in fibrous dysplasia. Skeletal Radiol 17:163-170, 1988

127. Tai PT, Craighead P, Bagdon F: Optimization of radiotherapy for patients with cranial chordoma. A review of dose-response ratios for photon techniques. Cancer 75:749-756, 1995

128. Takahashi H, Nakazawa S, Shimura T: Evaluation of postoperative intratumoral injection of bleomycin for craniopharyngioma in children. J Neurosurg 62:120-127, 1985

129. Teo C, Dornhoffer J, Hanna E, et al: Application of skull base techniques to pediatric neurosurgery. Childs Nerv Syst 15: 103-109, 1999

130. Thomassin JM, Braccini F: [Role of imaging and endoscopy in the follow up and management of cholesteatomas operated by closed technique.] Rev Laryngol Otol Rhinol 120:75-81, 1999 (Fre)

131. Tomita T: Management of craniopharyngiomas in children. Pediatr Neurosci 14:204-211, 1988

132. Tomita T, McLone DG: Radical resections of childhood craniopharyngiomas. Pediatr Neurosurg 19:6-14, 1993
133. Ueda H, Nakashima T, Nakata S: Surgical strategy for cholesteatoma in children. Auris Nasus Larynx 28:125-129, 2001

134. Uretzky ID, Mair EA, Schoem SR: Endoscopically guided midfacial degloving in infants for removal of congenital and acquired midfacial masses. Int J Pediatr Otorhinolaryngol 46:145-158, 1998

135. Van Den Abbeele T, Elmaleh M, Herman P, et al: Transnasal endoscopic repair of congenital defects of the skull base in children. Arch Otolaryngol Head Neck Surg 125:580-584, 1999

136. Vanden Abeele D, Coen E, Parizel PM, et al: Can MRI replace a second look operation in cholesteatoma surgery? Acta Otolaryngol 119:555-561, 1999

137. Vyramuthu N, Benton TF: The management of craniopharyngioma. Clin Radiol 34:629-632, 1983

138. Wen DY, Seljeskog EL, Haines SJ: Microsurgical management of craniopharyngiomas. Br J Neurosurg 6:467-474, 1992

139. White SJ, Wright CG, Robinson KS, et al: Effect of topical hyaluronic acid on experimental cholesteatoma. Am J Otolaryngol 16:312-318, 1995

140. Wiatrak BJ, Koopmann CF, Turrisi AT: Radiation therapy as an alternative to surgery in the management of intracranial juvenile nasopharyngeal angiofibroma. Int J Pediatr Otorhinolaryngol 28:51-61, 1993

141. Wold LE, Laws ER Jr: Cranial chordomas in children and young adults. J Neurosurg 59:1043-1047, 1983

142. Wright CG, Bird LL, Meyerhoff WL: Effect of 5-fluorouracil in cholesteatoma development in an animal model. Am J Otolaryngol 12:133-138, 1991

143. Yasargil MG, Curcic M, Kis M, et al: Total removal of craniopharyngiomas. Approaches and long-term results in 144 patients. J Neurosurg 73:3-11, 1990

Manuscript received March 19, 2002.

Accepted in final form April 29, 2002.

Address reprint requests to: James T. Rutka, M.D., Ph.D., Division of Neurosurgery, Suite 1502, The Hospital for Sick Children, 555 University Avenue, Toronto, Ontario M5G 1X8, Canada. email: james.rutka@sickkids.ca. 